\title{
Phenol Adsorption from Dilute Aqueous Solutions by Carbons
}

\author{
Elena Fernandez, Suzana Gotovac, Deirdre Hugi-Cleary, Victoria López-Ramóna, \\ and Fritz Stoeckli*
}

\section{Dedicated to Professor Jean-Baptiste Donnet (UHA, Mulhouse) on his 80th birthday}

Abstract: The adsorption of phenol from dilute aqueous solutions by seven activated carbons and one non-porous carbon black is reported. It is confirmed that the equilibrium can be described by a modified Dubinin-Radushkevich-Kaganer equation, with exponent $n=4$ and $E_{S}=(1.03 \pm 0.18) E_{0}$. At low equilibrium concentrations, phenol and its derivatives are adsorbed as monolayers by both non-porous and porous carbons. However, water is preferentially adsorbed on the oxygen-containing surface complexes, which reduces the area available to phenol and its derivatives by $71 \mathrm{~m}^{2}$ per mmol of surface oxygen.

Keywords: Activated carbon · Aqueous solutions · Dubinin · Phenol adsorption

\section{Introduction}

In view of its industrial and environmental importance, adsorption of phenol and related compounds from dilute aqueous solutions is one of the most studied systems in liquid-phase applications of activated carbons. Today, it is known that the adsorption process depends on different parameters, but the chemical nature of the adsorbent (in the present case carbon) and its surface area play a major role [1][2].

The adsorption equilibrium is described by the adsorption isotherm in solution, a function which relates the amount $\mathrm{N}_{\mathrm{a}}$ ad-

${ }^{*}$ Correspondence: Prof. F. Stoeckli Institut de Chimie, Université de Neuchâtel Av. de Bellevaux 51

CH-2007 Neuchâtel

Tel.: +4132718 2425

Fax: +41327182511

E-Mail: Fritz.Stoeckli@unine.ch

aDepartamento de Quimica Inorganica y Organica

Universidad de Jaen

E-23071 Jaen, Spain sorbed by the solid at temperature $\mathrm{T}$ and concentration $\mathrm{c}_{\mathrm{eq}}$. So far, most authors have used expressions such as the Langmuir or the Freundlich isotherms [3-5]. However, these isotherms contain empirical parameters and, for a given carbon, predictions are difficult, in particular at other temperatures. As shown recently by Stoeckli et al. [6][7] Dubinin's theory [8] provides the background for a simple and efficient description for the adsorption of phenol and related compounds from dilute aqueous solutions, as well as from concentrated solutions.

As shown elsewhere [6], for equilibrium concentrations $\mathrm{c}_{\mathrm{eq}}<1000$ to 3000 ppm, the adsorption equilibrium of phenol from dilute solutions can be described by Eqn. (1)

$\mathrm{N}_{\mathrm{a}}\left(\mathrm{T} ; \mathrm{c}_{\mathrm{eq}}\right)=\mathrm{N}_{\mathrm{am}} \exp \left\{-\left[\mathrm{RT} \ln \left(\mathrm{c}^{*} / \mathrm{c}_{\mathrm{eq}}\right) / \mathrm{E}_{\mathrm{s}}\right]^{4}\right\} \quad$ (1)

$\mathrm{N}_{\mathrm{am}}$, usually in mmol $\mathrm{g}^{-1}$, is the saturation capacity of the solid and $\mathrm{c}^{*}$ is the saturation concentration at temperature T. A great advantage of Eqn. (1) is the fact that the so-called characteristic energy $E_{s}$ is temperature-independent, at least over a reasonable temperature range. This is clearly shown by the analysis of the data provided by Leyva-Ramos et al. [5], for adsorption by a typical activated carbon between 283 and $313 \mathrm{~K}$. Consequently, the adsorption equilibrium can be predicted over a range of concentrations and temperatures, with the help of Eqn. (1) and two specific parameters, the monolayer capacity for phenol $\mathrm{N}_{\mathrm{am}}$ and the characteristic energy $\mathrm{E}_{\mathrm{s}}$ of the carbon under investigation.

In the present paper we show, on the basis of further systematic studies, how parameters $\mathrm{N}_{\mathrm{am}}$ and $\mathrm{E}_{\mathrm{s}}$ can be estimated from the structural characteristic of the carbons. This new development is based on the fact that for porous [6][9] and nonporous [10][11] carbons adsorption of phenolic compounds from dilute aqueous solutions is limited to a monolayer. (On the other hand, in the case of concentrated phenolic solutions, one observes a volume filling of the micropores [9][12]). Moreover, a clear correlation has been established between $\mathrm{E}_{\mathrm{s}}$ and its equivalent $\mathrm{E}_{\mathrm{o}} \mathrm{ob}$ tained in the standard characterization of microporous carbons by vapour adsorption.

The adsorption of vapours by activated carbons is described within the framework of Dubinin's theory [7][8]. At temperature $\mathrm{T}$ and relative pressure $\mathrm{p} / \mathrm{p}_{\mathrm{s}}$, the isotherm is given by the so-called Dubinin-Astakhov (DA) equation,

$\mathrm{N}_{\mathrm{a}}(\mathrm{T} ; \mathrm{p})=\mathrm{N}_{\mathrm{ao}} \exp \left\{-\left[\mathrm{RT} \ln \left(\mathrm{p}_{\mathrm{s}} / \mathrm{p}\right) / \mathrm{E}\right]^{\mathrm{n}}\right\}$

The limiting value $\mathrm{N}_{\text {ао }}$ corresponds to the filling of the micropores (or nanopores, according to the modern terminology). Their volume, usually in the range of 0.3 to 
$0.6 \mathrm{~cm}^{3} \mathrm{~g}^{-1}$, is $\mathrm{W}_{\mathrm{o}}=\mathrm{N}_{\mathrm{ao}} \mathrm{V}_{\mathrm{m}}$, assuming that $\mathrm{V}_{\mathrm{m}}$ is equal to the molar volume of the liquid (or the solid) at the corresponding temperature. Exponent $\mathrm{n}$ corresponds to the width of the adsorption energy distribution [7][8] and for most standard active carbons, exponent $\mathrm{n}=2$. On the other hand, smaller and larger values correspond respectively to relatively heterogeneous and homogeneous systems. Eqn. (1) is an extension of (2) for the case of monolayer adsorption from solution, where relative pressures are replaced by relative concentrations $\mathrm{c}_{\mathrm{eq}} / \mathrm{c}^{*}$.

For activated carbons, the reference characteristic energy $\mathrm{E}_{\mathrm{o}}=\mathrm{E}\left(\mathrm{C}_{6} \mathrm{H}_{6}\right)$, obtained for the adsorption of benzene, is related to the average micropore-width $\mathrm{L}_{\mathrm{o}}$ of the (locally) slit-shaped micropores pores:

$\mathrm{L}_{\mathrm{o}}(\mathrm{nm})=10.8 /\left(\mathrm{E}_{\mathrm{o}}-11.4 \mathrm{~kJ} \mathrm{~mol}^{-1}\right)$

Simple geometric considerations suggest that the corresponding surface area of the micropores is:

$\mathrm{S}_{\mathrm{mi}}\left(\mathrm{m}^{2} \mathrm{~g}^{-1}\right)=2000 \mathrm{~W}_{\mathrm{o}}\left(\mathrm{cm}^{3} \mathrm{~g}^{-1}\right) / \mathrm{L}(\mathrm{nm})$

Eqns. (3) and (4) have been established on the basis of various techniques [8][13] and recently confirmed by computer simulations [14].

Carbons also possess an external (nonmicroporous) surface area $S_{e}$ which can be assessed during the routine characterization of industrial activated carbons by using comparison plots. Consequently, the true surface area $\mathrm{S}_{\text {tot }}=\mathrm{S}_{\mathrm{mi}}+\mathrm{S}_{\mathrm{e}}$ of a given carbon is readily available. For carbons containing small amounts of surface oxygen, it is therefore possible to predict the monolayer capacity for phenol on the basis of its molecular surface area $A_{m}$ (phenol) = $45 \cdot 10^{-20} \mathrm{~m}^{2}$ per molecule [6] or $271 \mathrm{~m}^{2}$ $\mathrm{mmol}^{-1}$ :

$$
\begin{aligned}
\mathrm{N}_{\mathrm{am}}\left(\mathrm{mmol} \mathrm{g}^{-1}\right)= & \mathrm{S}_{\mathrm{tot}}\left(\mathrm{m}^{2} \mathrm{~g}^{-1}\right) / \\
& 271\left(\mathrm{~m}^{2} \mathrm{mmol}^{-1}\right)
\end{aligned}
$$

As shown recently [9], if oxygen is present on the surface of the carbon, water is preferentially adsorbed by the oxygencontaining centres and the surface area accessible to phenol is reduced, on average, by $71 \mathrm{~m}^{2}$ per mmol of oxygen [O]. This means that the available surface area is

$$
\begin{aligned}
\mathrm{S}_{\text {free }}\left(\mathrm{m}^{2} \mathrm{~g}^{-1}\right)= & \mathrm{S}_{\text {tot }}\left(\mathrm{m}^{2} \mathrm{~g}^{-1}\right) \\
& -71\left(\mathrm{~m}^{2} \mathrm{~g}^{-1}\right)[\mathrm{O}]\left(\mathrm{mmol} \mathrm{g}^{-1}\right)
\end{aligned}
$$

This value has to be used to estimate the real value of $\mathrm{N}_{\mathrm{am}}$.

Furthermore, as shown below, a systematic study suggests that the specific parameter $E_{s}$ of Eqn. (1) is related to the standard characteristic energy $\mathrm{E}_{0}$. This means that, in the case of untreated carbons, the adsorption of phenol from dilute solutions can be predicted on the basis of the standard characteristics of the carbon, $\mathrm{E}_{\mathrm{o}}$ and $\mathrm{W}_{\mathrm{o}}$ and Eqns. (1) and (5)-(6).

\section{Results and Discussion}

The present study is based on seven well-characterized activated carbons and one non-porous reference carbon black (Table). As seen in the Table, relatively small corrections were introduced, to take into account the reduction of the surface area caused by the surface oxygen [O] $(0.3$ to $3.2 \mathrm{mmol} \mathrm{g}^{-1}$ for the active carbons of the present study). The adsorption of phenol from aqueous solutions was carried out at $298 \mathrm{~K}$, following the procedure described in detail for samples N234-G and PC-R [6]. The results obtained for these two samples are in agreement with earlier determinations.

The comparison of the experimental values of $\mathrm{E}_{\mathrm{s}}$ and $\mathrm{E}_{\mathrm{o}}$ leads to a ratio $\mathrm{E}_{\mathrm{s}} / \mathrm{E}_{\mathrm{o}}=$ $1.03 \pm 0.18$ (8 values). This correlation, which includes the non-porous carbon black, shows no particular trend and, to a first approximation, one may assume that $\mathrm{E}_{\mathrm{s}}=1.03 \mathrm{E}_{\mathrm{o}}$. With the help of the data in the
Table, it is therefore possible to estimate the amount of phenol $\mathrm{N}_{\mathrm{a}}$ adsorbed by a given carbon at different relative equilibrium concentrations $\mathrm{c}_{\mathrm{eq}} \mathrm{c}^{*}$, by using a modified version of Eqn. (1),

$$
\mathrm{N}_{\mathrm{a}}\left(\mathrm{T} ; \mathrm{c}_{\mathrm{eq}}\right)=\mathrm{N}_{\left.\left.1.03 \mathrm{E}_{\mathrm{o}}\right]^{4}\right\}} \exp \left\{-\left[\mathrm{RT} \ln \left(\mathrm{c} * / \mathrm{c}_{\mathrm{eq}}\right) /\right.\right.
$$

where $\mathrm{N}_{\mathrm{am}}$ is given by Eqn. (5)-(6).

As seen in the Table and illustrated by the Fig., the monolayer capacities $\mathrm{N}_{\mathrm{am}}$ estimated with the help of Eqn. (6) lead to a good correlation with the experimental values. This means that Eqn. (7) can be used for a reasonable assessment of the removal of phenol from dilute aqueous solutions in the presence of an active carbon filter challenged by a given initial concentration of phenol $\mathrm{c}_{i}$ and at a temperature T. On the basis of a simple mass-balance, Eqn. (7) will provide information on the final equilibrium conditions. However, depending on the dynamic conditions, the adsorption kinetics must also be considered for a finer prediction of the filter's performance (The adsorption rate tends to decrease for carbons with smaller average micropore sizes $\mathrm{L}$, i.e. higher $\mathrm{E}_{\mathrm{o}}$ values).

As shown recently [6], the adsorption of various phenolic compounds such as 3aminophenol, 4-cresol, 4-nitrophenol and 3-chlorophenol, from dilute aqueous solutions, also follows Eqn. (7) and leads to scaling factor $\beta_{\mathrm{s}}=\mathrm{E}_{\mathrm{s}} / \mathrm{E}_{\mathrm{s}}$ (phenol) between 0.84 and 1.03. This means that Eqn. (7) can be extended, formally at least, to include this type of compound and it becomes

$$
\begin{aligned}
\mathrm{N}_{\mathrm{a}}\left(\mathrm{T} ; \mathrm{c}_{\mathrm{eq}}\right)= & \mathrm{N}_{\mathrm{am}} \exp \left\{-\left[\mathrm{RT} \ln \left(\mathrm{c} * / \mathrm{c}_{\mathrm{eq}}\right) /\right.\right. \\
& \left.\left.\beta_{\mathrm{s}} 1.03 \mathrm{E}_{\mathrm{o}}\right]^{4}\right\}
\end{aligned}
$$

Eqn. (8) should provide a reasonable assessment of the amounts of phenol and of

\begin{tabular}{|c|c|c|c|c|c|c|c|c|}
\hline & $\mathrm{N}-234 \mathrm{G}$ & U-03 & BV-46-ox & FO2 & BV-46 & XC-72 & PC-R & CMS \\
\hline $\mathrm{E}_{0}\left[\mathrm{~kJ} \mathrm{~mol}^{-1}\right]$ & 17.8 & 17.8 & 19.8 & 18.9 & 21.4 & 22.4 & 23.9 & 28.7 \\
\hline $\mathrm{E}_{\mathrm{s}}(\mathrm{phe})_{\exp }\left[\mathrm{kJ} \mathrm{mol}^{-1}\right]$ & 20.01 & 20.0 & 20.9 & 23.7 & 22.4 & 23.3 & 19.1 & 22.4 \\
\hline $\mathrm{E}_{\mathrm{s}} / \mathrm{E}_{0}$ & 1.12 & 1.12 & 1.06 & 1.25 & 1.05 & 1.04 & 0.80 & 0.78 \\
\hline $\mathrm{S}_{\text {tot }}^{\mathrm{s}}\left[\mathrm{m}^{2} \mathrm{~g}^{-1}\right]$ & 92 & 700 & 765 & 865 & 853 & 250 & 1097 & 829 \\
\hline $\mathrm{S}_{\text {free }}\left[\mathrm{m}^{2} \mathrm{~g}^{-1}\right]$ & 92 & 619 & 534 & 782 & 830 & 219 & 969 & 736 \\
\hline $\mathrm{N}_{\mathrm{am}}(\mathrm{phe})_{\exp }\left[\mathrm{mmol} \mathrm{g}^{-1}\right]$ & 0.34 & 2.71 & 2.14 & 3.73 & 2.89 & 0.437 & 3.75 & 2.83 \\
\hline $\mathrm{N}_{\mathrm{am}}(\mathrm{phe})_{\text {calc }}\left[\mathrm{mmol} \mathrm{g}^{-1}\right]$ & 0.32 & 2.28 & 1.97 & 2.89 & 3.06 & 0.805 & 3.58 & 2.72 \\
\hline
\end{tabular}
its derivatives removed from dilute aqueous solutions by activated carbons. Obviously, Eqn. (5) and (6), used for the evaluation of the monolayer capacities $\mathrm{N}_{\mathrm{am}}$, have

Table. Main structural and adsorption characteristics of the carbons. $\mathrm{N}_{\mathrm{am}}(\mathrm{phe})_{\text {calc }}$ is obtained from $\mathrm{S}_{\text {free }}$ 


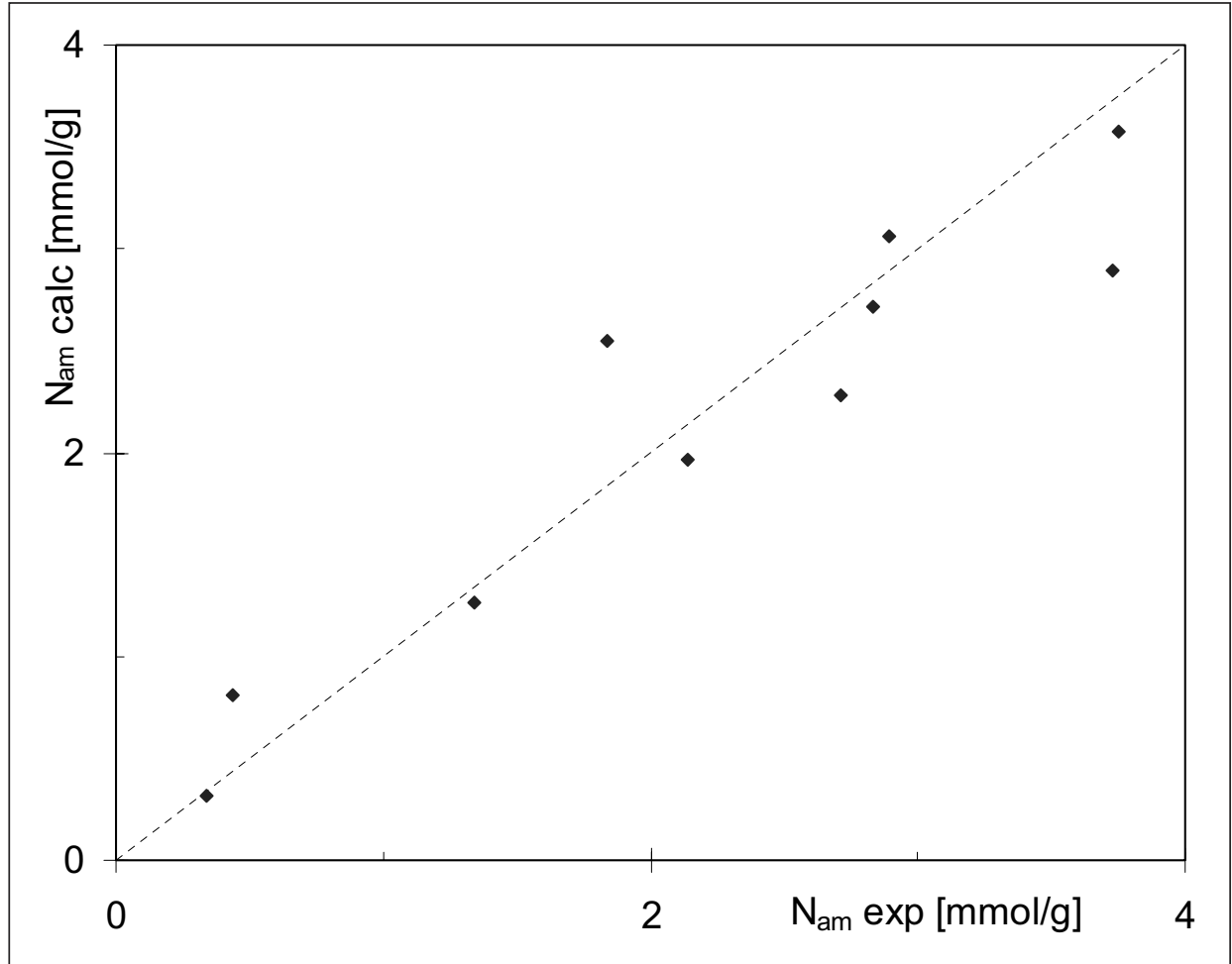

Fig. Correlation between $\mathrm{N}_{\mathrm{am}} \mathrm{mmol} / \mathrm{g}$, calculated using Eqns. (5), (6) and $\mathrm{N}_{\mathrm{am}}$ experimental, $\mathrm{mmol} / \mathrm{g}$

to be modified accordingly, to take into account the differences in molecular surface areas of the different compounds [6]. However, a more systematic study is required and results will be reported in due course.

\section{Acknowledgements}

The authors wish to thank the Swiss national Science Foundation (SNSF) for financial support and for a $\mathrm{PhD}$ grant (S.G.) (project no 2063594.00)

Received: July 14, 2003

[1] M. Franz, H.A. Arafat, N.G. Pinto, Carbon 2000, 38, 1807.

[2] O.P. Mahajan, C. Moreno Castilla, P. L. Walker, Separation Science and Technology 1980, 15(10), 1733.

[3] H. Teng, C.-T. Hsieh, Ind. Eng. Chem. Res. 1998, 37, 3618

[4] R.S. Jueang, F.C. Wu, R.L. Tseng, J. Chem. Eng. Data 1996, 41, 487.

[5] R. Leyva-Ramos, J.H. Soto-Zuñiga, J. Mendoza-Barrón, R. Guerrero-Coronado, Adsorp. Sci. Technol. 1999, 17, 533.

[6] F. Stoeckli, M. V. López-Ramón, C. Moreno-Castilla, Langmuir 2001, 17 , 3301.

[7] F. Stoeckli, Rus. Chem. Bull. Int. Ed. 2001, 50, 2265.

[8] F. Stoeckli, in 'Porosity in Carbons-Characterization and Application', Ed. J. Patrick, Arnold London, 1996, 67.

[9] E. Fernandez, D. Hugi-Cleary, M.V. Lopez Ramon, F. Stoeckli, Langmuir 2003, 19 , in press.

[10] D.D. Singh, Indian J. of Chemistry 1971 , 9, 1369.
[11] B.R. Puri, S.S. Bhardawaj, U. Gupta, J. Indian Chem. Soc. 1976, 8, 1095.

[12] F. Stoeckli, D. Hugi-Cleary, Rus. Chem. Bull. Int. Ed. 2001, 50, 2060.

[13] F. Stoeckli, M.V. López-Ramón, D. HugiCleary, A. Guillot, Carbon 2001, 39, 1115.

[14] F. Stoeckli, A Guillot, A. Slasli, D. HugiCleary, Carbon 2002, 40, 211 